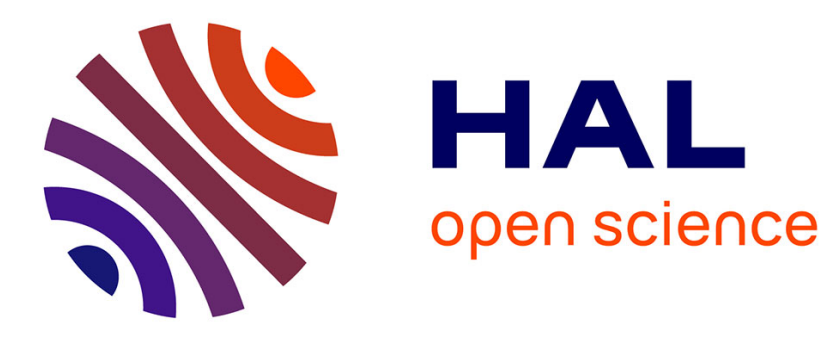

\title{
Supramolecular Hydrogels from in situ Host-Guest Inclusion between Chemically Modified Cellulose Nanocrystals and Cyclodextrin
}

\author{
Ning Lin, Alain Dufresne
}

\section{- To cite this version:}

Ning Lin, Alain Dufresne. Supramolecular Hydrogels from in situ Host-Guest Inclusion between Chemically Modified Cellulose Nanocrystals and Cyclodextrin. Biomacromolecules, 2013, 14 (3), pp.871-880. 10.1021/bm301955k . hal-02098609

\section{HAL Id: hal-02098609 https://hal.science/hal-02098609}

Submitted on 12 Apr 2019

HAL is a multi-disciplinary open access archive for the deposit and dissemination of scientific research documents, whether they are published or not. The documents may come from teaching and research institutions in France or abroad, or from public or private research centers.
L'archive ouverte pluridisciplinaire HAL, est destinée au dépôt et à la diffusion de documents scientifiques de niveau recherche, publiés ou non, émanant des établissements d'enseignement et de recherche français ou étrangers, des laboratoires publics ou privés. 


\title{
Supramolecular Hydrogels from in situ Host-Guest Inclusion between Chemically Modified Cellulose Nanocrystals and Cyclodextrin
}

\author{
Ning Lin, Alain Dufresne*
}

Grenoble Institute of Technology (Grenoble INP) -The International School of Paper, Print Media and Biomaterials (Pagora), CS10065, 38402 Saint Martin d'Hères Cedex, France

KEYWORDS: cellulose nanocrystals, chemical modification, host-guest inclusion, cyclodextrin, hydrogels 
ABSTRACT: Using grafted $\beta$-cyclodextrin as targeting sites, Pluronic polymers have been introduced on the surface of cellulose nanocrystals by means of inclusion interaction between $\beta$ cyclodextrin and hydrophobic segment of the polymer. Because of steric stabilization effect, surface poly(ethylene glycol) chains facilitate the dispersion and compatibility of nanocrystals, which also enhance the loading levels of nanocrystals in the hydrogel system. Meanwhile, uncovered poly(ethylene glycol) segments render the participating inclusion of $\alpha$-cyclodextrin for the architecture of in situ hydrogels. Surface grafting and inclusion reactions were proved by solid ${ }^{13} \mathrm{C}$ NMR and FTIR. Grafting efficiency of $\beta$-cyclodextrin and inclusion efficiency of Pluronic on the surface of nanocrystals were confirmed by UV spectroscopy and elemental analysis. A significant enhancement of the structural and thermal stability of in situ hydrogels with high loading levels of modified nanocrystals $(>5.77 \mathrm{wt} \%)$ was observed by rheological analysis. Further study reveals the performance and behavior of hydrogels under different $\mathrm{pH}$ environment. Finally, in situ hydrogels were used as drug carrier for in vitro release of doxorubicin, and exhibit the behavior of prolonged drug release with special release kinetics. 


\section{INTRODUCTION}

Cellulose nanocrystal $(\mathrm{CN})$ has attracted a great deal of interest in material science due to its appealing intrinsic properties including nano-dimensions, high surface area, unique morphology, low density and mechanical strength, as well as availability, renewability and biodegradability. ${ }^{1}$ Abundant hydroxyl groups on the surface of $\mathrm{CN}$ are suitable for physical adsorption or diverse chemical modifications including esterification, etherification, oxidation, silylation, and polymer grafting. ${ }^{2-4}$ Modified nanocrystals with alterative surface properties were not only widely used as nanofiller to enhance various matrices through the development of composites, ${ }^{5,6}$ but also for the exploration of advanced functional nanomaterials. ${ }^{7,8}$ Recently, much more attention focused on the application of $\mathrm{CN}$ in the field of biomaterials, such as fluorescent labels for bioimaging, ${ }^{9,10}$ labeled carriers for DNA detection ${ }^{11}$ and photodynamic therapy, ${ }^{12}$ enzyme immobilization, ${ }^{13,14}$ photobactericidal material, ${ }^{15,16}$ biomedical scaffold ${ }^{17,18}$ and hydrogels. ${ }^{19,20}$ Hydrogel materials have shown wide potential applications in the biomaterial field, such as drug delivery, because of their safety, biocompatibility and biodegradability. Among hydrogel systems, hydrogels based on supramolecular self-assembly between cyclodextrin (CD) and polymeric chains are most widely studied, and have promising application prospects. Particularly, supramolecular hydrogels formed with the host-guest inclusion between polymer and CD molecules, exhibit reversible thixotropism, making them suitable for syringeable drug delivery application. ${ }^{21}$ Although $\mathrm{CN}$ has attracted wide attention in the utilization as physical reinforcing filler in various hydrogel matrices, such as cyclodextrin, ${ }^{22}$ agarose, ${ }^{23,24}$ poly(vinyl alcohol $),{ }^{25}$ poly $(N$-isopropyl acrylamide), ${ }^{26}$ poly(2-hydroxyethylmethacrylate), ${ }^{27}$ to the best of our knowledge, only one

example of pristine $\mathrm{CN}$ in cyclodextrin-based hydrogel has been reported. ${ }^{22}$ However, in this study, due to the strong hydrophilicity and easy self-assembling property of this highly- 
crystalline nanoparticle, the loading level of $\mathrm{CN}$ in cyclodextrin hydrogel was quite low $(<2.5$ $\mathrm{wt} \%)^{22}$ Recently, it was shown that a weak reinforcing percolating network from surface modified $\mathrm{CN}$ can be formed in aqueous gels. ${ }^{28}$ If only introducing $\mathrm{CN}$ with extremely low contents, it is believed that the rigid network formed by the linkage of these nanoparticles cannot be obtained, and even weaken the promising nano-reinforcing effect for ensuing materials.

Herein, with the strategy of surface chemical modification of $\mathrm{CN}$ with Pluronic polymers (poloxamer), the loading level of $\mathrm{CN}$ was elevated, and the dispersion of the nanoparticles was improved. As shown in Figure 1A, $\beta$-cyclodextrin $(\beta-\mathrm{CD})$ was first covalently grafted on the surface of $\mathrm{CN}$ using epichlorohydrin (EPI) as coupling agent, which is a typical strategy for the synthesis of cyclodextrin derivatives. Afterwards, Pluronic polymer was immobilized on modified $\mathrm{CN}$ by inclusion of the hydrophobic polymeric segments in grafted $\beta$-CD (Figure 1B). This process was performed with the assistant of ultrasonic treatment to induce the inclusion. Pluronic polymers used here were tri-block copolymers with different molecular weights (Pluronic F68 or F108), both bearing hydrophobic poly(propylene glycol) (PPG) and hydrophilic poly(ethylene glycol) (PEG) segments (PEG- $b$-PPG- $b$-PEG). The inclusion of the hydrophobic PPG chain segments in the inner cavity of $\beta$-CD allows closely connecting the polymer and the nanoparticle, contrarily to surface physical adsorption of polymers on CN. Finally, with the in situ "host-guest" inclusion of uncovered PEG chains in smaller size $\alpha$-cyclodextrin $(\alpha-\mathrm{CD})$ molecules, the architecture of supramolecular hydrogel based on modified $\mathrm{CN}$ can be formed (Figure 1C). This work is an attempt to design a novel hydrogel with the construction of participating $\mathrm{CN}$ in hydrogels via the interactions between compatible grafted chains and polymeric matrix. The key factor of this strategy emphasized on the use of block copolymer and cyclodextrin with different sizes and selected inclusive interactions. Pluronic polymers were 
semi-chemically immobilized on the surface of $\mathrm{CN}$, which provided the possibility of good dispersion, and in situ inclusion of nanocrystals in the hydrogel system. Moreover, the similar structure of $\mathrm{CN}$ and $\mathrm{CD}$ both from polysaccharide preserved the biocompatibility and biodegradability of ensuing materials, which endowed a "green" note to the hydrogel with promising mechanical property, thermal stability and sustained-drug release behavior. These supramolecular hydrogels formed with rigid nanocrystals can promote the potential application of nanocellulose in the field of biomedical technology and nanoscience.

\section{MATERIALS AND METHODS}

\section{Materials.}

Native cotton fibers were obtained from Whatman filter paper. $\alpha$-Cyclodextrin $(\alpha-C D), \beta$ Cyclodextrin $\left(\beta\right.$-CD), Pluronic polymers F68 $\left(\mathrm{PEG}_{76}-b-\mathrm{PPG}_{30}-b-\mathrm{PEG}_{76}, M_{\mathrm{n}}=8400\right)$, Pluronic polymers $\mathrm{F} 108\left(\mathrm{PEG}_{133}-b-\mathrm{PPG}_{50}-b-\mathrm{PEG}_{133}, M_{\mathrm{n}}=14600\right)$, phenolphthalein and sodium carbonate $\left(\mathrm{Na}_{2} \mathrm{CO}_{3}\right)$ were reagent grade from Sigma-Aldrich. Epichlorohydrin $(99 \%)$ was obtained from Acros Organics. Sodium hydroxide $(\mathrm{NaOH})$ and sulfuric acid $\left(\mathrm{H}_{2} \mathrm{SO}_{4}, 98 \%\right)$ of laboratory grade were purchased from Carl-Roth and used without further treatment. Doxorubicin hydrochloride (Dox. $\mathrm{HCl}$ ) was chosen as the model drug, and purchased from Sigma-Aldrich.

\section{Extraction of cellulose nanocrystals (CN).}

Cellulose nanocrystals $(\mathrm{CN})$ were prepared by $\mathrm{H}_{2} \mathrm{SO}_{4}$ hydrolysis of native cotton fiber, according to our previous literature. ${ }^{29}$ The fiber was milled with a laboratory milling device to obtain a fine particulate substance and extracted in $2 \mathrm{wt} \%$ aqueous $\mathrm{NaOH}$ solution $(12.5 \mathrm{~g}$ fibers for $500 \mathrm{~mL}$ solution) for $12 \mathrm{~h}$ at room temperature and then filtered and rinsed with distilled water. Acid 
hydrolysis was performed at $45{ }^{\circ} \mathrm{C}$ with $65 \mathrm{wt} \% \mathrm{H}_{2} \mathrm{SO}_{4}$ (preheated), for 45 min under mechanical stirring (12.5 g fibers for $250 \mathrm{~mL}$ solution). Amorphous or paracrystalline regions of cellulose were preferentially hydrolyzed, whereas crystalline regions that have higher resistance to acid attack remained intact. The suspension was diluted with ice cubes to stop the reaction and washed until neutrality by successive centrifugations at $10000 \mathrm{rpm}$ (rotation per minute) for 10 min each step and dialyzed against distilled water for five days. After dialysis, the $\mathrm{CN}$ dispersion was completed by ultrasonic treatment using a Branson sonifier, and finally the released $\mathrm{CN}$ powder was obtained by freeze-drying.

\section{Synthesis of $\beta$-cyclodextrin-grafted cellulose nanocrystals $[(\beta) C D$-g-CN (1)].}

The grafting reaction of $\beta$-cyclodextrin on the surface of cellulose nanocrystals was accomplished using epichlorohydrin (EPI) as coupling agent through a one-step procedure (Figure 1A). ${ }^{30}$ Firstly, $4.0 \mathrm{~g} \mathrm{NaOH}$ was dissolved in $20 \mathrm{~mL}$ distilled water as the aqueous $\mathrm{NaOH}$ solution. $\beta$-CD (10.351 g, $9.12 \mathrm{mmol})$ was dissolved in the prepared $\mathrm{NaOH}$ solution. At the same time, $1.0 \mathrm{~g} \mathrm{CN}$ was dispersed in another $20 \mathrm{~mL}$ distilled water as homogeneous suspension, added in the $\beta$-CD alkaline solution and stabilized for $30 \mathrm{~min}$. The desired amount of EPI (5.96 $\mathrm{mL}, 76 \mathrm{mmol}$ ) was thus added into the reaction medium, and the reaction was allowed to proceed at $40{ }^{\circ} \mathrm{C}$ for $6 \mathrm{~h}$. It should be pointed out that the EPI/CD molar ratio was controlled at about 8.3 (below 10) to avoid self-crosslinking of $\beta$-CD. Meanwhile, the effective $\mathrm{NaOH}$ solution concentration was controlled at about $16 \mathrm{wt} \%$, to facilitate the grafting reaction. ${ }^{30}$ After modification, the suspension was centrifuged at $10000 \mathrm{rpm}$ for $15 \mathrm{~min}$, and washed with distilled water repeatedly until neutrality to remove both ungrafted $\beta$ - $\mathrm{CD}$ and residual $\mathrm{NaOH}$. Finally, the grafted product $[(\beta) \mathrm{CD}-\mathrm{g}-\mathrm{CN}(1)]$ was obtained as powder by freeze-drying for 2 days. 
The grafting efficiency of $\beta$-CD on the surface of $\mathrm{CN}$ was confirmed with the methods of weight measurement and photometric titration. Three grafting experiments were repeated for weight measurement. After grafting $\beta$-CD, the weights of products $(\beta) \mathrm{CD}$-g-CN were $1.1579 \mathrm{~g}, 1.1684$ $\mathrm{g}$ and $1.1368 \mathrm{~g}$, correspond ing to a grafting efficiency of $15.79 \mathrm{wt} \%, 16.84 \mathrm{wt} \%$ and $13.68 \mathrm{wt} \%$, respectively. According to the results of weight measurement, the average $\beta$-CD grafting efficiency was $15.44 \mathrm{wt} \%$. Further accurate measurement from photometric titration was also used to investigate the $\beta$-CD grafting efficiency $(G E \%)$ for $(\beta) \mathrm{CD}-\mathrm{g}-\mathrm{CN}$.

\section{Inclusion complex of $(\beta) \mathrm{CD}$-g-CN/Pluronic polymers (2).}

Theoretically, due to the dimensions as well as hydrophilic and hydrophobic property of $\beta$-CD and Pluronic polymers, one grafted $\beta$-CD host one guest Pluronic chain for the inclusion. In this work, expecting for complete inclusion, the molar ratio between grafted $\beta$-CD and Pluronic polymer was regulated as 1:2. The protocol for the preparation of inclusion complex $[(\beta) \mathrm{CD}$-g$\mathrm{CN} /$ Pluronic (2)] was as follow: $500 \mathrm{mg}$ powdered $(\beta) \mathrm{CD}$-g-CN $(74.4 \mu \mathrm{mol}$ grafted $\beta$-CD according to the $16.89 \mathrm{wt} \%$ grafting efficiency from photometric titration analysis) was dispersed in $10 \mathrm{~mL}$ distilled water under mechanical stirring for $12 \mathrm{~h}$ and then ultrasonicated for 30 min. Meanwhile, $1.25 \mathrm{~g}(148.8 \mu \mathrm{mol})$ Pluronic F68 $\left(\mathrm{PEG}_{76}-b-\mathrm{PPG}_{30}-b-\mathrm{PEG}_{76}\right)$ was dissolved in another $40 \mathrm{~mL}$ distilled water. It should be pointed out that because of the hydrophobic interactions among PPG chains, Pluronic polymers may self-associate in water to form micelles. ${ }^{31}$ To avoid it, a dilute aqueous solution of Pluronic polymer $(45.7 \mathrm{mg} / \mathrm{mL})$ was used for the inclusion between $(\beta) \mathrm{CD}$-g-CN and Pluronic polymers. The Pluronic solution was protected against light by an aluminum foil and weakly stirred for $12 \mathrm{~h}$ at room temperature. Then, the aqueous suspension containing $(\beta) \mathrm{CD}$-g-CN was added dropwise into the Pluronic solution and 
the mixture was submitted to mild ultrasonic assistant treatment for $20 \mathrm{~min}$ and mechanical stirring for $72 \mathrm{~h}$ at room temperature. During the reaction, the hydrophobic PPG chains can insert into the hydrophobic cavity of $\beta-\mathrm{CD}$ and form the stable inclusion complex resulting from the physical crosslinking interaction. ${ }^{32}$ As for Pluronic $\mathrm{F} 108\left(\mathrm{PEG}_{133}-b-\mathrm{PPG}_{50}-b-\mathrm{PEG}_{133}\right)$, due to different molecular weight, 2.173 g F108 polymer was mixed with $500 \mathrm{mg}(\beta) \mathrm{CD}$-g-CN suspension.

The suspension of inclusion complex was centrifugated at $10000 \mathrm{rpm}$ for $10 \mathrm{~min}$ to collect the precipitate and the supernatant. The powdered $(\beta) \mathrm{CD}-\mathrm{g}-\mathrm{CN} /$ Pluronic precipitate was washed with distilled water and the supernatant was analyzed with FTIR tracing method. Because of the hydrophilic property of PEG chains, free Pluronic polymer dissolves in water, but inclusive Pluronic polymer forms stable suspensions. This process of successive solubilizationcentrifugation was performed repeatedly until the disappearance of the characteristics bands of Pluronic from the result of FTIR. The content of inclusive Pluronic was confirmed by elemental analysis as shown in Table S1.

\section{Supramolecular hydrogels via in situ inclusion $[(\beta)$ CD-g-CN/Pluronic $]-[\alpha(C D) / P l u r o n i c](3)$.}

The architecture of in situ supramolecular hydrogel was realized with the "host-guest" inclusion between $\alpha-\mathrm{CD}$, Pluronic polymer and modified $\mathrm{CN}$. The preparation method of in situ hydrogels

CN-CD/F68 (3) was adapted from previous literature. ${ }^{33,34}$ The powdered $(\beta)$ CD-g-CN/F68 was dispersed in $3.5 \mathrm{~mL}$ water, with specific F68 polymer content according to the inclusion efficiency from the result of elemental analysis. Another controlled weight of pure F68 was added in the suspension of modified $\mathrm{CN}$ under mild stirring at $4{ }^{\circ} \mathrm{C}$ until a stable suspension was obtained. It was reported that the viscosity of Pluronic aqueous solution remains unchanged 
under such temperature conditions. ${ }^{33}$ Another saturated solution of $\alpha$-CD $(1.5 \mathrm{~mL}$ water $)$ was added in the mixture of modified $\mathrm{CN}$ and pure F68, in which the concentrations of Pluronic F68 and $\alpha-\mathrm{CD}$ were $13 \mathrm{w} / \mathrm{v}$ and $9.7 \mathrm{w} / \mathrm{v}$, respectively. The mixture was ultrasonicated for $10 \mathrm{~min}$ and then conditioned overnight at room temperature for gelation. A similar method was used for the preparation of supramolecular hydrogels $\mathrm{CN}-\mathrm{CD} / \mathrm{F} 108$. Neat hydrogels of $\mathrm{F} 68 / \alpha-\mathrm{CD}$ and F108/ $\alpha$-CD were also prepared with the same approach and concentration as the reference. The composition, concentration and codification of the various hydrogels are summarized in Table S2.

To prove the capability of inclusion between $(\beta) \mathrm{CD}-\mathrm{g}-\mathrm{CN} /$ Pluronic and $\alpha-\mathrm{CD}$, the complex of ( $\beta)$ CD-g-CN/Pluronic- $\alpha(C D)$ was prepared independently, isolated by centrifugation and washed with a limited amount of water to remove free $\alpha-\mathrm{CD}^{35}$

\section{Characterization and Analys es}

\section{Solid state ${ }^{13} \mathrm{C}$ cross polarization-magic angle spinning spectroscopy $\left({ }^{13} \mathrm{C}\right.$ CP-MAS NMR).}

${ }^{13} \mathrm{C}$ CP-MAS NMR experiment for the proof of grafting of $\beta-\mathrm{CD}$ on the surface of $\mathrm{CN}$ was performed on a AVANCE400 solid instrument spectrometer with a MAS rate of $6 \mathrm{kHz}$, at 75.5 $\mathrm{MHz}$ carbon frequency and at room temperature. The contact time for $\mathrm{CP}$ was $1 \mathrm{msec}$ with a proton 90 pulse of $5.5 \mu \mathrm{sec}$ and decoupling power of $45 \mathrm{kHz}$. The delay time after the acquisition of the FID signal was 2 sec. The chemical shifts were calibrated with the hexamethylbenzene standard methyl resonance at $17.3 \mathrm{ppm}$.

\section{UV-Vis spectros copy.}


The content of grafted $\beta$-CD in $(\beta) \mathrm{CD}$-g-CN (I) was analyzed with a Shimadzu UV 2401-(PC) UV-Vis spectrophotometer. Phenolphthalein (phe) was used as indicator to detect the change of absorbency. Firstly, together with sodium carbonate solution, pure phe solution, phe solution containing $50 \mathrm{mg}$ unmodified $\mathrm{CN}$, and phe solution containing $50 \mathrm{mg}(\beta) \mathrm{CD}$-g-CN were well dispersed and stabilized for $20 \mathrm{~h}$. The phe absorption experiment was performed on the UV spectrophotometer using $1 \mathrm{~cm}$ thick quartz cuvette with wavelengths ranging from $450 \mathrm{~nm}$ to $650 \mathrm{~nm}$ to confirm the characteristic absorbed wavelength $\left(\lambda_{\max }\right)$ of phe solution.

The standard curve for the weight of $\beta$-CD and absorbency of phe solution was quantified with the photometric titration method. $2 \mathrm{~mL}$ phe solution and $2 \mathrm{~mL}$ sodium carbonate solution were added in \#1 volumetric flask ( $25 \mathrm{~mL}$ ), and set the volume to the mark with distilled water. $1 \mathrm{~mL}$, $2 \mathrm{~mL}, 3 \mathrm{~mL}, 4 \mathrm{~mL}, 5 \mathrm{~mL} \beta$-CD solutions were added in $\# 2, \# 3$, \#4, \#5, and \#6 volumetric flask $(25 \mathrm{~mL})$, respectively; and then $10 \mathrm{~mL}$ distilled water was added in each flask. After that, both 2 $\mathrm{mL}$ phe solution and $2 \mathrm{~mL}$ sodium carbonate solution were added in each flask (except \#1), and finally set the volume to the mark with distilled water. All solutions were submitted to absorption analysis at the wavelength of $552 \mathrm{~nm}\left(\lambda_{\max }\right)$, and the standard curve and equation from the weight of $\beta-\mathrm{CD}(W, \mathrm{mg})$ and absorbency of phe $(A)$ was determined.

Similar experiments were carried out for the measurement of grafted $\beta$-CD content. Five samples of $5 \mathrm{mg}, 10 \mathrm{mg}, 20 \mathrm{mg}, 30 \mathrm{mg}, 40 \mathrm{mg}(\beta) \mathrm{CD}$-g-CN in $10 \mathrm{~mL}$ distilled water were added in another $\# 7, \# 8, \# 9$, \#10, and \#11 volumetric flask ( $25 \mathrm{~mL})$, respectively, and then both $2 \mathrm{~mL}$ phe solution and $2 \mathrm{~mL}$ sodium carbonate solution were added. All mixtures were set the volume to the mark of volumetric flask with distilled water and stabilized for $20 \mathrm{~h}$. The absorbency at the wavelength of $552 \mathrm{~nm}$ was recorded and corresponded to the weight content of grafted $\beta$-CD 
according to the standard equation. Finally, the $\beta$-CD grafting efficiency of $\mathrm{CN}-g-(\beta) \mathrm{CD}$ (I) can be calculated.

\section{Fourier transform infrared spectroscopy (FTIR).}

Infrared spectra were recorded at room temperature on a FTIR Perkin-Elmer Spectrum One spectrometer to characterize $\mathrm{CN},(\beta) \mathrm{CD}$-g-CN, $(\beta) \mathrm{CD}-\mathrm{g}-\mathrm{CN} /$ Pluronic and $\beta$-CD. Freeze-dried powders were analyzed as $\mathrm{KBr}$ pellets ( $1 \mathrm{wt} \%$ in anhydrous $\mathrm{KBr}$ ) using a spectral width ranging from 4000 to $400 \mathrm{~cm}^{-1}$ with a $2 \mathrm{~cm}^{-1}$ resolution and an accumulation of 20 scans. On the other hand, during the preparation of inclusion complex $(\beta) \mathrm{CD}$-g-CN/Pluronic), the supernatants containing free Pluronic polymers were collected from the process of successive solubilizationcentrifugation. The supernatant was carefully dropped on the surface of neat $\mathrm{KBr}$ compressingtablet, and water was vaporized at room temperature for $12 \mathrm{~h}$. The $\mathrm{KBr}$ tablet together with Pluronic polymers on the surface were also characterized by FTIR.

\section{Elemental analysis.}

Elemental analysis was performed at Analysis Central Service of the Centre National de la Recherche Scientifique (Vernaison, France). The carbon, oxygen and hydrogen element contents for both $(\beta) \mathrm{CD}$-g-CN/F68 and $(\beta) \mathrm{CD}$-g-CN/F108 samples were measured. The results from elemental analysis were used to determine the content of inclusive Pluronic polymers for $(\beta) \mathrm{CD}$ g-CN/Pluronic (IE\%) according to formula (1):

$I E \%_{\text {Pluronic }}+(1-I E \%) C_{C N-g-(\beta) C D}=C_{C N-g-(\beta) C D / \text { Pluronic }}$ 
where $\mathrm{C}$ is the relative carbon content in the sample; $I E \%$ is the inclusion efficiency for inclusive Pluronic polymers for grafted $\beta$-CD. The precision of the measurement is considered to be $0.3 \%$ for $\mathrm{C}$ and $\mathrm{H}$ elements and $0.5 \%$ for $\mathrm{O}$ element.

\section{X-ray diffraction analysis (XRD).}

$\mathrm{XRD}$ was used to prove the possibility of inclusion interactions between $(\beta) \mathrm{CD}$-g-CN/Pluronic and $\alpha-\mathrm{CD}$, which was recorded on a Philips PW $1720 \mathrm{X}$-ray generator operated at $30 \mathrm{kV}$ and 20 $\mathrm{mA}$ with $\mathrm{Cu} \mathrm{K} \alpha$ radiation $(\lambda=0.154 \mathrm{~nm})$ in a range of $2 \theta=3-50^{\circ}$ using a fixed time mode with a step interval of $0.02^{\circ}$.

\section{Transmission electron (TEM) and optical micros copy.}

The dimensions and morphologies of pristine CN were observed by TEM. Drops of 0.001 wt $\%$ cellulose suspensions were deposited on glow-discharged carbon-coated TEM grids. The specimens were then negatively stained with $2 \%$ uranyl acetate. After complete drying under room conditions, specimens were observed using a Philips CM200 electron microscope operating at $80 \mathrm{kV}$.

The morphology of hydrogel crystals was directly observed by optical microscopy. The hydrogel was dropped on the glass slide, and formed after standing a period of time in aqueous solution. Excess water was removed carefully with the absorption by the edge of filter paper, and the morphology was observed after the complete dryness.

\section{Rheological analysis.}


Viscoelastic behavior of hydrogels was evaluated on a Rheolyst Physica MCR-301 rheometer. Viscosity of the hydrogel was recorded applying a flow cycle consisting in a continuously increasing shear rate ramp at $20{ }^{\circ} \mathrm{C}$ from 0.05 to $10 \mathrm{~s}^{-1}$ for $4 \mathrm{~min}$. The storage $\left(\mathrm{G}^{\prime}\right)$ and the loss ( $\left.\mathrm{G}^{\prime \prime}\right)$ moduli were recorded under the shear stress of $100 \mathrm{~Pa}$ in the range of $0.5-100 \mathrm{rad} / \mathrm{s}$ angular frequency interval using a cone-plate geometry (diameter $20 \mathrm{~mm}$, angle $1^{\circ}$ ). The dependence of $\mathrm{G}^{\prime}$ and $\mathrm{G}^{\prime \prime}$ on temperature was evaluated at $20 \mathrm{rad} / \mathrm{s}$ and $50 \mathrm{~Pa}$ in the range of $20-70{ }^{\circ} \mathrm{C}$.

The influence of $\mathrm{pH}$ conditions on the property of hydrogel was investigated to determine the loss $\left(\mathrm{G}^{\prime \prime}\right)$ and storage $\left(\mathrm{G}^{\prime}\right)$ moduli with different $\mathrm{pH}$ ranging from 1 to 11 . The adjustment of $\mathrm{pH}$ conditions was achieved by the addition of $\mathrm{HCl}$ and $\mathrm{NH}_{4} \mathrm{OH}$, which was a negligible amount. Tests were conducted in triplicate at a fixed frequency of $1 \mathrm{~Hz}$ with $50 \mathrm{~Pa}$ shear stress at $20^{\circ} \mathrm{C}$.

\section{In vitro release of doxorubicin $\cdot \mathrm{HCl}$ from hydrogels.}

Doxorubicin $\cdot \mathrm{HCl}(1.0 \mathrm{mg})$ was dissolved in $2 \mathrm{~mL}$ distilled water, and then $(\beta) \mathrm{CD}$-g-CN/Pluronic and controlled amount of Pluronic was added. The mixture was kept at $4{ }^{\circ} \mathrm{C}$ overnight in order to obtain a homogeneous suspension. Afterwards, $\alpha$-CD was added to induce in situ host-guest inclusion and form stable hydrogel. The study of in vitro drug release was performed in water at $37^{\circ} \mathrm{C}$. The hydrogel was placed in a test tube with $20 \mathrm{~mL}$ water, and then incubated in a shaking water bath. Solution of $3 \mathrm{~mL}$ aliquots containing released drug was withdrawn from the testing tube periodically. The volume of solution in the tube was kept constant by adding another $3 \mathrm{~mL}$ water after each sampling. The cumulative release ratio of doxorubicin $\cdot \mathrm{HCl}$ from hydrogels was measured by UV/Vis spectrophotometer (Shimadzu UV 2401-(PC)) at the absorbency of 481 $\mathrm{nm}$. The experiment for in vitro drug release was performed in triplicate. 


\section{RESULTS AND DISCUSSION}

\section{Chemical grafting of $\beta-C D$ on the surface of $C N$.}

The ${ }^{13} \mathrm{C}$ CP-MAS spectra of $\mathrm{CN}, \beta-\mathrm{CD}$ and $(\beta) \mathrm{CD}$-g-CN are shown in Figure 2 . The chemical shifts of carbon atoms from original $\mathrm{CN}$ were assigned to $\mathrm{C} 1$ (105 ppm), $\mathrm{C} 4$ (88 ppm), C2,3,5 (71-75 ppm), and C6 (65 ppm). Possessing the same glucose structure units, the characteristic chemical shifts related to $\mathrm{C}^{\prime}, 3^{\prime}, 5^{\prime}$ for $\beta$-CD superimpose with cellulose. However, because of different monomer unit quantity and molecular conformations, the presence of $\beta$-CD can be determined by the position shifts of C1' (102 ppm), C4' (81 ppm), and C6' (64 ppm). As shown in the spectrum of $(\beta) \mathrm{CD}-\mathrm{g}-\mathrm{CN}$, all carbon characteristics from both $\mathrm{CN}$ and $\beta$-CD can be identified, which indicates the surface grafting of $\beta$-CD and integrity of $\mathrm{CN}$.

Under $\mathrm{pH}>10$ condition, phenolphthalein (phe) aqueous solution shows red color, which darkens when increasing phe concentration. It was reported that the hydrophobic group of phe molecule can insert into the hydrophobic cavity of $\beta-\mathrm{CD}$, which reduce the free phe concentration in solution, and finally cause the decline of absorbency from light color solution. As shown in the $\mathrm{UV}-\mathrm{V}$ is spectra of Figure $3 \mathrm{~A}$, the impact of pristine $\mathrm{CN}$ was negligible on phe molecule, which showed tiny absorption and slight decrease of absorbency in comparison with neat phe solution. However, the introduction of $(\beta) \mathrm{CD}-\mathrm{g}-\mathrm{CN}$ caused a sharp reduction of absorbency, which indicates that the hydrophobic cavity of $\beta$-CD includes plentiful phe molecules. Based on BeerLambert law, within a range of controlled concentration, the content of grafted $\beta-\mathrm{CD}$ on the surface of $\mathrm{CN}$ can be detected according to the absorbency of alkaline phe solution. The absorbency of phenolphthalein $(A)$ showed a negative correlation with the concentration of 
grafted $\beta-\mathrm{CD}\left(C_{\beta-\mathrm{CD}}, \mathrm{mg} / \mathrm{mL}\right)$, which was in agreement with the weight of grafted $\beta$-CD $\left(W_{\beta-\mathrm{CD}}\right.$, $\mathrm{mg}$ ) because of the same volume of solution $(25 \mathrm{~mL})$ used in the experiment. The standard curve and equation between $A$ and $W_{\beta \text {-CD }}$ are shown in Figure 3B. Different quantities of $(\beta) \mathrm{CD}$-g-CN $(5,10,20,30,40 \mathrm{mg})$ were added in the phe solution, and the content of grafted $\beta$-CD was calculated from absorbency according to the equation reported in Figure 3B. As shown in Figure $3 \mathrm{C}$, the average value of $\beta$-CD grafting efficiency $(G E \%)$ was determined as $16.89 \mathrm{wt} \%$ using this photometric titration method, which is almost in agreement with the result of weight measurement $(15.44 \mathrm{wt} \%)$.

\section{Inclusion of Pluronic polymers in grafted $\beta-C D$.}

Although possessing similar glucose unit structure, the grafting and inclusion reaction between $\mathrm{CN}, \beta-\mathrm{CD}$ and Pluronic polymers can be investigated by the change of peak intensity for specific bond stretching bands. Figure 4 (A and B) shows the FTIR spectra of $\mathrm{CN}$ before and after grafting or inclusion reaction. With the surface grafting of $\beta$-CD on $\mathrm{CN}$, the intensity of three peaks located at 1163,1113 , and $1059 \mathrm{~cm}^{-1}$ decreased, which are ascribed to antisymmetric bridge oxygen stretching, antisymmetric in-phase ring stretching and C-O stretching for cellulose, respectively. Furthermore, another $\mathrm{C}-\mathrm{O}$ stretching band at $1031 \mathrm{~cm}^{-1}$ broadened after surface grafting. These results are in agreement with other reports for cyclodextrin-EPI cellulose. ${ }^{30}$ By comparing the spectra for $(\beta) \mathrm{CD}-\mathrm{g}-\mathrm{CN}$ and $(\beta) \mathrm{CD}$-g-CN/Pluronic, it is interesting to note that the intensity of the peaks located at 1031 and $898 \mathrm{~cm}^{-1}$ slightly increased, which can be attributed to the emerging C-O groups and antisymmetric out-of-phase stretching carbon from the inclusive PEG-PPG-PEG polymer. However, it was very important to confirm the inclusion reaction between grafted $\beta$-CD and Pluronic polymers, and prove the complete 
removal of free and surface physically adsorbed Pluronic polymers on nanocrystals. An experiment of FTIR tracing was designed to investigate the effect of the process of successive solubilization-centrifugation during the preparation of inclusion complex $((\beta) \mathrm{CD}$-gCN/Pluronic). As shown in Figure 4(C), after the post-treatment of purification for three times, the spectra for the supernatant (F3) from washed $(\beta) \mathrm{CD}-\mathrm{g}-\mathrm{CN} / \mathrm{Pluronic}$ did not exhibited any characteristics of Pluronic polymers, which proved the availability of free Pluronic removal using this method. On the other hand, the physical mixture of CN/Pluronic was also prepared using the same concentration, and treated with the same purification treatment. By comparing the spectra of $\mathrm{CN}$ (R-Pluronic) and pure $\mathrm{CN}$, it was observed that they are nearly similar (as shown in Figure 4D), which indicates that the purification treatment can also effectively remove the polymer physically adsorbed on the surface of nanocrystals. It should be pointed out that because the main body of $(\beta) \mathrm{CD}$-g-CN is cellulose (only $16.89 \mathrm{wt} \%$ grafted $\beta$-CD), the possible physical adsorption of Pluronic was supposed to mainly occur on the surface of CN. Consequently, the above comparative experiments were carried on $\mathrm{CN}$ to prove the effect of purification.

The content or inclusion efficiency $(I E \%)$ of Pluronic polymer on the surface of $(\beta)$ CD-g$\mathrm{CN} /$ Pluronic complexes was determined by elemental analys is. As shown in Table S1, with the similar glucose unit structure $\left(\mathrm{C}_{6} \mathrm{H}_{10} \mathrm{O}_{5}\right), \mathrm{CN}$ and $\beta$-CD have the same theoretical values for the three element contents $(\mathrm{C}, \mathrm{O}$ and $\mathrm{H})$, resulting in small change of element contents for the grafted nanocrystals $[(\beta) \mathrm{CD}-\mathrm{g}-\mathrm{CN}]$. On the other hand, although presenting different molecular weights and polymer segments, there is a little difference in theoretical values for element contents between the two Pluronic polymers. Regarding experimental values of these original materials, because of the instrumental error and influence of hydrophily of cellulose and $\beta$-CD, some variance of the experimental values was inevitable for $\mathrm{CN}$ and $\beta-\mathrm{CD}$, which was mainly 
attributed to the adsorption of moisture $\left(\mathrm{H}_{2} \mathrm{O}\right)$ during the delivery and experiment. Therefore, the values of inclusion efficiency were confirmed mainly based on the data from carbon element, and calculated according to Equation (1). As shown in Table S1, the inclusion efficiency (IE\%) of Pluronic polymers for $(\beta) \mathrm{CD}-\mathrm{g}-\mathrm{CN} / \mathrm{F} 68$ and $(\beta) \mathrm{CD}$ - $\mathrm{g}-\mathrm{CN} / \mathrm{F} 108$ complexes were $12.25 \mathrm{wt} \%$ and $15.57 \mathrm{wt} \%$, respectively.

\section{Crystalline structure of inclusive complexes.}

The inclusion of polymeric chains in cyclodextrin can also be investigated with XRD analysis. The crystalline diffraction patterns of original materials and various inclusive complexes are presented in Figure 5. As shown in panel $\mathrm{A}$, the characteristic diffraction peaks of cellulose, $\beta$ $\mathrm{CD}$ and $\alpha-\mathrm{CD}$, on one hand, and Pluronic polymers on the other hand were assigned to the $2 \theta$ angles at $22.6^{\circ}, 12.9^{\circ}, 14.3^{\circ}$, and $19.1^{\circ}, 23.2^{\circ}$, respectively. The sharp diffraction peak for inclusive complexes located at about $20.0^{\circ}$ strongly supports the channel-type crystalline structure of the obtained polyrotaxanes (Figure 5B), which indicated that cyclodextrin underwent a solid-state phase transformation as it formed an inclusion compound with polymeric chains. ${ }^{36}$ Pluronic F108 with longer polymeric chains can include more $\alpha$-CD molecules than short Pluronic F68, which is reflected through the higher intensity for $(\beta)$ CD-g-CN/F108- $\alpha(\mathrm{CD})$ complex at $20.0^{\circ}$. On the other hand, by comparing the diffraction patterns of $(\beta) \mathrm{CD}-\mathrm{g}-$ $\mathrm{CN} /$ Pluronic and $(\beta) \mathrm{CD}$-g-CN/Pluronic- $\alpha(\mathrm{CD})$ complexes, the crystalline feature of $\alpha$-CD appeared with the emergence of a weak peak at $14.3^{\circ}$. In general, the inclusive complexes or hydrogels of cyclodextrin and polymers do not present the obvious crystalline features of cyclodextrin. However, in this case, the inclusion between $\alpha$-CD and PEG chains occurred at the surface of nanocellulose, which may induce the arrangement of inclusive chains (PEG/ $\alpha-\mathrm{CD})$, 
and cause the slight exhibition of $\alpha$-CD crystalline feature. This phenomenon also indicates the capability of inclusion between $(\beta) \mathrm{CD}$-g-CN/Pluronic and $\alpha-\mathrm{CD}$, which ensured the future in situ formation of hydrogels. In addition, the crystalline character of cellulose was covered in these patterns, which induced the broadening of the peak observed between $18^{\circ}$ and $25^{\circ}$. By magnifying the patterns, the traces of crystalline cellulose can be observed with a ill-defined peak located at about $22.6^{\circ}$, as shown in Figure 5C.

\section{Morphology and dimensions of $\mathrm{CN}$ and hydrogels.}

TEM was used to observe the morphology and dimensions of cellulose nanocrystals, as shown in Figure 6. Nanocrystals exhibited a typical rod-like morphology with a length of 200-400 nm and a diameter of $10-20 \mathrm{~nm}$ with an aspect ratio $(L / d)$ of about 18 . This result was in accordance with our previous report for the morphological observation of cellulose nanocrystals using atomic force microscopy (AFM) ${ }^{29}$ Generally, during the process of observation, the inclusion complex of $\alpha-\mathrm{CD} / \mathrm{PEG}$ hydrogel recrystallizes in water, and forms crystals of regular shapes with facets on microscope grid at room temperature. ${ }^{35}$ As shown in Figure 7, both in situ hydrogels derived from Pluronic F68 and F108 exhibited the regular appearance with rectangular morphology in the size range of ca. 10-20 $\mu \mathrm{m}$ long and 2-4 $\mu \mathrm{m}$ wide. In comparison with the F68-hydrogels (panels A and B), F108-hydrogels (panels C and D) show higher length (> $15 \mu \mathrm{m}$ ) and much coarser surface, which may be attributed to the longer PEG chains of Pluronic F108 in the hydrogel system.

\section{Rheological behavior of hydrogels.}

When modified $\mathrm{CN}$ were introduced into the architecture of hydrogels, these nanoparticles can participate to the in situ inclusion between polymers and cyclodextrin via the surface grafted 
polymeric chains, which endowed strong coupling between nanocrystals and hydrogel. On the other hand, if the loading level of added nanoparticles reaches a critical content, such as the percolation threshold $\left(v_{\mathrm{Rc}}\right)$, the strong interactions (such as hydrogen bonding) among nanoparticles should force them to associate/interact with each other for supporting the tridimensional percolating network. ${ }^{37}$ It is believed that both interactions are beneficial for the performance of the hydrogel, and should strengthen and improve the structural stability and rheological behavior of ensuing hydrogels. Before the discussion of rheological properties of in situ hydrogels, the value of $v_{\mathrm{Rc}}$ can be calculated with the dependence upon the aspect ratio $(L / d)$ of rod-like $\mathrm{CN}$ according to Equation (4):

$v_{R c}=\frac{0.7}{L / d}$

The $v_{\mathrm{Rc}}$ value is therefore inversely proportional to the aspect ratio of $\mathrm{CN}$. According to the observations from TEM, the value of $v_{\mathrm{Rc}}$ in this case was close to $3.89 \mathrm{vol} \%(6.09 \mathrm{wt} \%$ with the density of cotton cellulose $1.565 \mathrm{~g} / \mathrm{mg}$ ).

The rheological behavior of hydrogels was investigated on the basis of three aspects, including change of viscosity as a function of the shear rate, dependence of storage moduli $\left(G^{\prime}\right)$ and loss moduli $\left(G^{\prime \prime}\right)$ as a function of angular frequency and temperature. When subjected to flow experiments, all hydrogels exhibited the physical nature of gelation and were found to be thixotropic and reversible, as shown in Figure 8 (A and A'). Even for in situ hydrogel with the highest initial viscosity (CN-CD/F108-3), the viscosity of the hydrogel greatly reduced when increasing the shear rate. This property makes the hydrogels syringeable, which is useful and important for drug delivery systems. Two different effects on the rheological behavior of in situ hydrogels as a function of angular frequency were observed depending on the $\mathrm{CN}$ content as 
shown in Figure 8 (B and $\left.\mathrm{B}^{\prime}\right)$. With the addition of only $50 \mathrm{mg}$ modified $\mathrm{CN}$, the improvement of the mechanical properties of the hydrogel was unobvious ( $\mathrm{CN}-\mathrm{CD} /$ Pluronic-1) in comparison with the neat hydrogel (Pluronic/ $\alpha-C D)$. However, when the loading level increased above 100 $\mathrm{mg}$, the moduli of both F68- and F108-hydrogels were enhanced significantly. Meanwhile, with the introduction of enough modified $\mathrm{CN}$, the in situ hydrogels can maintain better structural stability in contrast to the sharp decrease of moduli observed for neat hydrogels under high angular frequency. The dependence of the hydrogel moduli as a function of temperature is shown in Figure $8\left(\mathrm{C}\right.$ and $\left.\mathrm{C}^{\prime}\right)$. The effect of introducing modified $\mathrm{CN}$ in hydrogels was more evident, and induced the promising thermal stability for in situ hydrogels contrarily to the strong variation induced by sol-gel transition for neat hydrogels. It should be pointed out that the F108-hydrogels commonly presented better mechanical properties and thermal stability than F68-hydrogels, which may be attributed to the longer polymeric chains with more inclusive cyclodextrin molecules for Pluronic F108. In addition, based on the rheological behavior of in situ hydrogels, it was interesting that the mechanical properties of $\mathrm{CN}-\mathrm{CD} / \mathrm{Pluronic}-2$ was similar to that of $\mathrm{CN}-$ $\mathrm{CD} /$ Pluronic-3, which indicates that the introduction of $\mathrm{CN}$ in the hydrogel $\mathrm{CN}-\mathrm{CD} / \mathrm{Pluronic}-2$ may be a critical point for the support of some special structure. According to the results of elemental analysis reported in Table $\mathrm{S} 2$, the true contents of $\mathrm{CN}$ in hydrogels $\mathrm{CN}-\mathrm{CD} / \mathrm{F} 68-2$ and $\mathrm{CN}-\mathrm{CD} / \mathrm{F} 108-2 \mathrm{were} 5.96 \mathrm{wt} \%$ and $5.77 \mathrm{wt} \%$, which was very close to the previously calculated percolation threshold $\left(v_{\mathrm{Rc}}, 6.09 \mathrm{wt} \%\right)$. It was believed that cellulose nanoparticles with adequate loading level could form the percolating network in the architecture of hydrogels, and properly improved the performance of in situ hydrogels.

The influence of different $\mathrm{pH}$ values on the properties ( $\mathrm{G}^{\prime}$ and $\left.\mathrm{G}^{\prime \prime}\right)$ of hydrogels was investigated under acidic, neutral and alkaline conditions. As shown in Figure 9A, under acidic conditions, in 
situ hydrogels $\mathrm{CN}-\mathrm{CD} / \mathrm{F} 68-2$ and $\mathrm{CN}-\mathrm{CD} / \mathrm{F} 68-3$ kept high moduli and stability, which was about 5 times higher than for neat hydrogels. The maximum values of $G^{\prime}$ for all hydrogels appeared in neutral condition $(\mathrm{pH}=7)$. However, when increasing the $\mathrm{pH}$ values to alkaline environment, the moduli for all hydrogels dropped sharply, which may be attributed to the higher solubility and dissolution of cyclodextrin in alkaline condition. Similar results can also be observed for the CNCD/F108 hydrogel system (Figure 9B). However, it was interesting that different from other hydrogels, hydrogel CN-CD/F108-3 preserved a storage moduli $\left(\mathrm{G}^{\prime}\right)$ at high levels, and seemed to possess the ability of alkaline resistance. Further study will focus on this interesting phenomenon.

\section{Drug release and mechanism study.}

Doxorubicin is an anticancer drug, which is widely used in the resistant of solid tumors, including breast cancer, ovarian carcinoma, transitional cell bladder carcinoma, and thyroid carcinoma. However, the non-negligible side effect, primarily the cardiotoxicity resulting from high concentration of drug in blood, demands ideal carrier for this drug for effective drug controlled release. ${ }^{38}$ As shown in Figure 10A, in situ hydrogels formed with participating modified $\mathrm{CN}$ (CN-CD/F68-2-Dox and CN-CD/F108-2-Dox) exhibited promising controlled release behavior with sustained release for about one week, whereas neat hydrogels (F68/ $\alpha-\mathrm{CD}$ and F108/ $\alpha-\mathrm{CD}$ ) displayed an initial burst release and shortened release period (only 2.5 days). The prolonged drug release for in situ hydrogels upon modified CN introduction was supposed to

result from two factors. As reported in our previous literature, ${ }^{39}$ rigid $\mathrm{CN}$ has been proved to induce physical "obstruction effect" in alginate-based microsphere for controlled drug release property. On the other hand, in this study, if the loading level of nanocrystals reaches the percolation threshold inducing a network structure with linkage among nanoparticles, it may 
provide another "locking effect" to delay the diffusion of doxorubicin molecules (as shown in Figure 10B). Both effects from modified nanocrystals led to the sustained drug release of in situ hydrogels. It is worth noting that when comparing the hydrogels formed with different Pluronic chains, there was no significant relation between the length of chains used in the hydrogel and drug release behavior. However, the final cumulative release ratio depended on the length of used Pluronic for hydrogels, which indicates the lower final cumulative release for hydrogels with longer Pluronic chains.

To prove the different release mechanisms for hydrogels, Ritger-Peppas equation was used to analyze the results of drug release:

$Q=k t^{n} \quad\left(\operatorname{In} Q=k^{\prime}+n \operatorname{In} t\right)$

where $Q$ is the amount of drug released at time $t ; k$ is a constant associated with the structural and geometrical characteristics of dosage form; $n$ is the release (diffusion) exponent, which depends on the release mechanism. It was reported that $n$ values approximating to 0.50 indicates a Fickian diffusion release; whereas $n$ value in the range of 0.50 to 0.85 represents both diffusion controlled release and non-Fickian diffusion release (anomalous transport). ${ }^{40}$ Estimated parameters and fitted equations for the various hydrogels with different compositions are shown in Table S3. It was shown that neat hydrogels (Pluronic/ $\alpha$-CD-Dox) underwent the common Fickian diffusion, but in situ hydrogels (CN/CD-Pluronic-Dox) exhibited an anomalous transport release mechanism. These results revealed the different effects and changes of in situ hydrogels with the introduction of modified nanocrystals compared to neat hydrogels.

\section{CONCLUSIONS}


This work was an attempt to use chemical modification methods to promote the compatibility and enhance the loading levels of cellulose nanocrystals in hydrogel materials. Meanwhile, uncovered polymeric chains render the participating inclusion of $\alpha$-cyclodextrin for the architecture of in situ hydrogels. Grafting efficiency of $\beta$-cyclodextrin on the surface of nanocrystals was confirmed by UV spectroscopy as $16.89 \mathrm{wt} \%$, and inclusion efficiency of Pluronic F68 and F108 polymers were measured by elemental analysis as $12.25 \mathrm{wt} \%$ and 15.57 wt $\%$, respectively. With the introduction of high loading levels of modified nanocrystals $(>5$ wt\%), a significant enhancement of structural and thermal stability of in situ hydrogels was observed from rheological analysis. Further study revealed the performance of hydrogels as drug carrier for in vitro release of doxorubicin, and exhibited the behavior of prolonged drug release with special release kinetics, which was attributed to the "obstruction effect" and "locking effect". Based on their performances and properties, these in situ hydrogels as syringeable drug delivery provide a scientific example for the application of biomass nanocrystals in the field of biomedical materials.

\section{AUTHOR INFORMATION}

* Corresponding author: Tel: +334768269 95; fax: +33476826933.

E-mail address: Alain.Dufresne@pagora.grenoble-inp.fr (A. Dufresne).

Notes: The authors declare no competing financial interest.

\section{ACKNOWLEDGMENTS}


The authors are grateful to Professor Jean-Luc Putaux (CERMAV-France) for the help and discussion on TEM analysis. This work is supported by the China Scholarship Council (CSC) under Grant No. 2011695007.

\section{ASSOCIATED CONTENT}

Supporting Information: Results of element analysis from Table S1, compositions of hydrogels from Table S2, and drug release mechanism from Table S3 are shown in Supporting Information section. This material is available free of charge via the Internet at http//pubs.acs.org.

\section{REFERENCES}

(1) Azizi Samir, M. A. S.; Alloin, F.; Dufresne, A. Biomacromolecules 2005, 6, 612-626.

(2) Habibi, Y.; Lucia, A. L.; Rojas, O. J. Chem. Rev. 2010, 110, 3479-3500.

(3) Klemm, D.; Kramer, F.; Moritz, S.; Lindström, T.; Ankerfors, M.; Gray, D.; Dorris, A. Angew. Chem. Int. Ed. 2011, 50, 5438-5466.

(4) Moon, R. J.; Martini, A.; Nairn, J.; Simonsen, J.; Youngblood, J. Chem. Soc. Rev. 2011, 40, 3941-3994.

(5) Dufresne, A. Molecules 2010, 15, 4111-4128.

(6) Eichhorn, S. J.; Dufresne, A.; Aranguren, M.; Marcovich, N. E.; Capadona, J. R.; Rowan, S. J.; Weder, C.; Thielemans, W.; Roman, M.; Renneckar, S.; Gindl, W.; Veigel, S.; Keckes, J.; Yano, H.; Abe, K.; Nogi, M.; Nakagaito, A. N.; Mangalam, A.; Simonsen, J.; Benight, A. S.; Bismarck, A.; Berglund, L. A.; Peijs, T. J. Mater. Sci. 2010, 45, 1-33.

(7) Lin, N.; Huang, J.; Dufresne, A. Nanoscale 2012, 4, 3274-3294.

(8) Lam, E.; Male, K. B.; Chong, J. H.; Leung, A. C. W.; Luong, J. H. T. Trends Biotechnol. 2012, 30, 283-290. 
(9) Dong, S.; Roman, M. J. Am. Chem. Soc. 2007, 129, 13810-13811.

(10) Mahmoud, K. A.; Mena, J. A.; Male, K. B.; Hrapovic, S.; Kamen A.; Luong, J. H. T. ACS Appl. Mater. Interfaces 2010, 2, 2924-2932.

(11) Liu, H.; Wang, D.; Song, Z.; Shang, S. Cellulose 2011, 18, 67-74.

(12) Drogat, N.; Granet, R.; Le Morvan, C.; Bégaud-Grimaud, G.; Krausz, P.; Sol, V. Bioorg. Med. Chem. Lett. 2012, 22, 3648-3652.

(13) Mahmoud, K. A.; Male, K. B.; Hrapovic, S.; Luong, J. H. T. ACS Appl. Mater. Interfaces 2009, 1, 1383-1386.

(14) Edwards, J. V.; Prevost, N. T.; Condon, B.; French, A.; Wu, Q. Cellulose 2012, 19, 495506.

(15) Feese, E.; Sadeghifar, H.; Gracz, H. S.; Argyropoulos, D. S.; Ghiladi, R. A. Biomacromolecules 2011, 12, 3528-3539.

(16) Carpenter, B. L.; Feese, E.; Sadeghifar, H.; Argyropoulos, D. S.; Ghiladi, R. A. Photochem. Photobiol. 2012, 88, 527-536.

(17) Wang, Y.; Chang, C.; Zhang, L. Macromol. Mater. Eng. 2010, 295, 137-145.

(18) Gatenholm, P.; Klemm, D. MRS Bulletin 2010, 35, 208-213.

(19) Chang, C.; Zhang, L. Carbohydr. Polym. 2011, 84, 40-53.

(20) Sannino, A.; Demitri, C.; Madaghiele, M. Materials 2009, 2, 353-373.

(21) Li, J. NPG Asia Mater. 2010, 2, 112-118.

(22) Zhang, X.; Huang, J.; Chang, P. R.; Li, J.; Chen, Y.; Wang, D.; Yu, J.; Chen, J. Polymer 2010, 51, 4398-4407.

(23) Osorio-Madrazo, A.; Eder, M.; Rueggeberg, M.; Pandey, J. K.; Harrington, M. J.; Nishiyama, Y.; Putaux, J.-L.; Rochas, C.; Burgert, I. Biomacromolecules 2012, 13, 
$850-856$.

(24) Bica, C. I. D.; Borsali, R.; Rochas, C.; Geissler, E. Macromolecules 2006, 39, 3622-3627.

(25) Abitbol, T.; Johnstone, T.; Quinn, T. M.; Gray, D. G. Soft Matter 2011, 7, 373-2379.

(26) Cha, R.; He, Z.; Ni, Y. Carbohydr. Polym. 2012, 88, 713-718.

(27) Karaaslan, M. A.; Tshabalala, M. A.; Yelle, D. J.; Buschle-Diller, G. Carbohydr. Polym. 2011, 86, 192-201.

(28) Way, A. E.; Hsu, L.; Shanmuganathan, K.; Weder, C.; Rowan, S. J. ACS Macro Lett. 2012, $1,1001-1006$.

(29) Lin, N.; Bruzzese, C.; Dufresne, A. ACS Appl. Mater. Interfaces 2012, 4, 4948-4959.

(30) Zhao, Q.; Wang, S.; Cheng, X.; Yam, R. C. M.; Kong, D.; Li, R. K. Y. Biomacromolecules 2010, 11, 1364-1369.

(31) Mortensen, K.; Pedersen, J. S. Macromolecules 1993, 26, 805-812.

(32) Tsai, C.-C.; Leng, S.; Jeong, K.-U.; Van Horn, R. M.; Wang, C.-L.; Zhang, W.-B.; Graham, M. J.; Huang, J.; Ho, R.-M.; Chen, Y.; Lotz, B.; Cheng, S. Z. D. Macromolecules 2010, 43, 9454-9461.

(33) Li, J.; Li, X.; Zhou, Z.; Ni, X.; Leong, K. W. Macromolecules 2001, 34, 7236-7237.

(34) Simões, S. M. N.; Veiga, F.; Torres-Labandeira, J. J.; Ribeiro, A. C. F.; Sandez-Macho, M. I.; Concheiro, A.; Alvarez-Lorenzo, C. Eur. J. Pharm. Biopharm. 2012, 80, 103-112.

(35) He, L.; Huang, J.; Chen, Y.; Xu, X.; Liu, L. Macromolecules 2005, 38, 3845-3851.

(36) Peet, J.; Rusa, C. C.; Hunt, M. A.; Tonelli, A. E.; Balik, C. M. Macromolecules 2005, 38, $537-541$

(37) Dufresne, A. Can. J. Chem. 2008, 86, 484-494.

(38) Xun, W.; Wu, D.-Q.; Li, Z.-Y.; Wang, H.-Y.; Huang, F.-W.; Cheng, S.-X.; Zhang, X.-Z.; 
Zhuo R.-X. Macromol. Biosci. 2009, 9, 1219-1226.

(39) Lin, N.; Huang, J.; Chang, P. R.; Feng L.; Yu, J. Colloid. Surface. B 2011, 85, 270-279.

(40) Ritger, P. L.; Peppas, N. A. J. Control. Release 1987, 5, 37-42. 


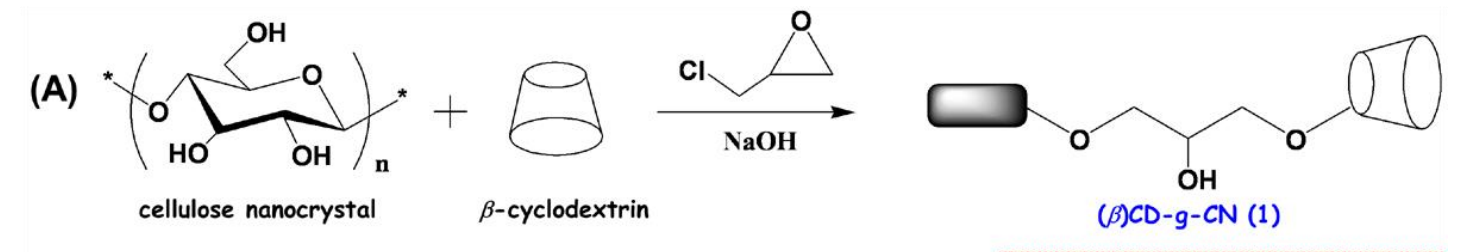

(B)

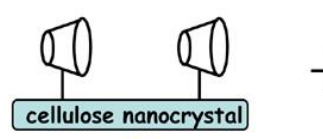

(1)
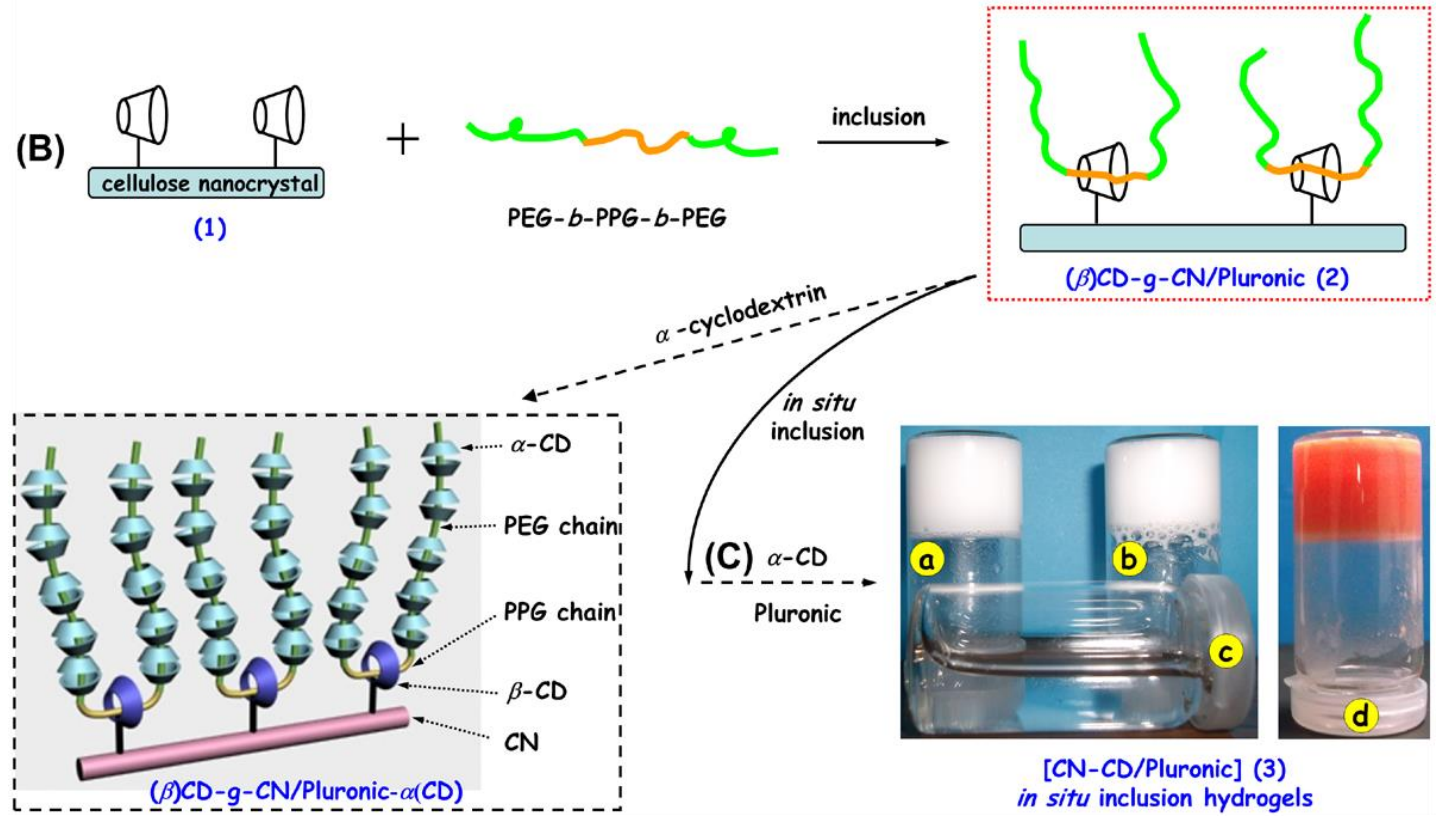

Figure 1. Synthesis pathway for (A) $\beta$-cyclodextrin grafting on cellulose nanocrystal $(\beta) \mathrm{CD}-\mathrm{g}-\mathrm{CN}$; (B) inclusion complex of $(\beta) \mathrm{CD}$-g-CN and Pluronic polymers; (C) supramolecular hydrogels from in situ inclusion between $(\beta) \mathrm{CD}$-g-CN/Pluronic and $\alpha$-CD: (a) hydrogel CN-CD/F68-2, (b) hydrogel CN-CD/F108-2, (c) water, (d) drugloaded hydrogel CN-CD/F108-2-Dox. 


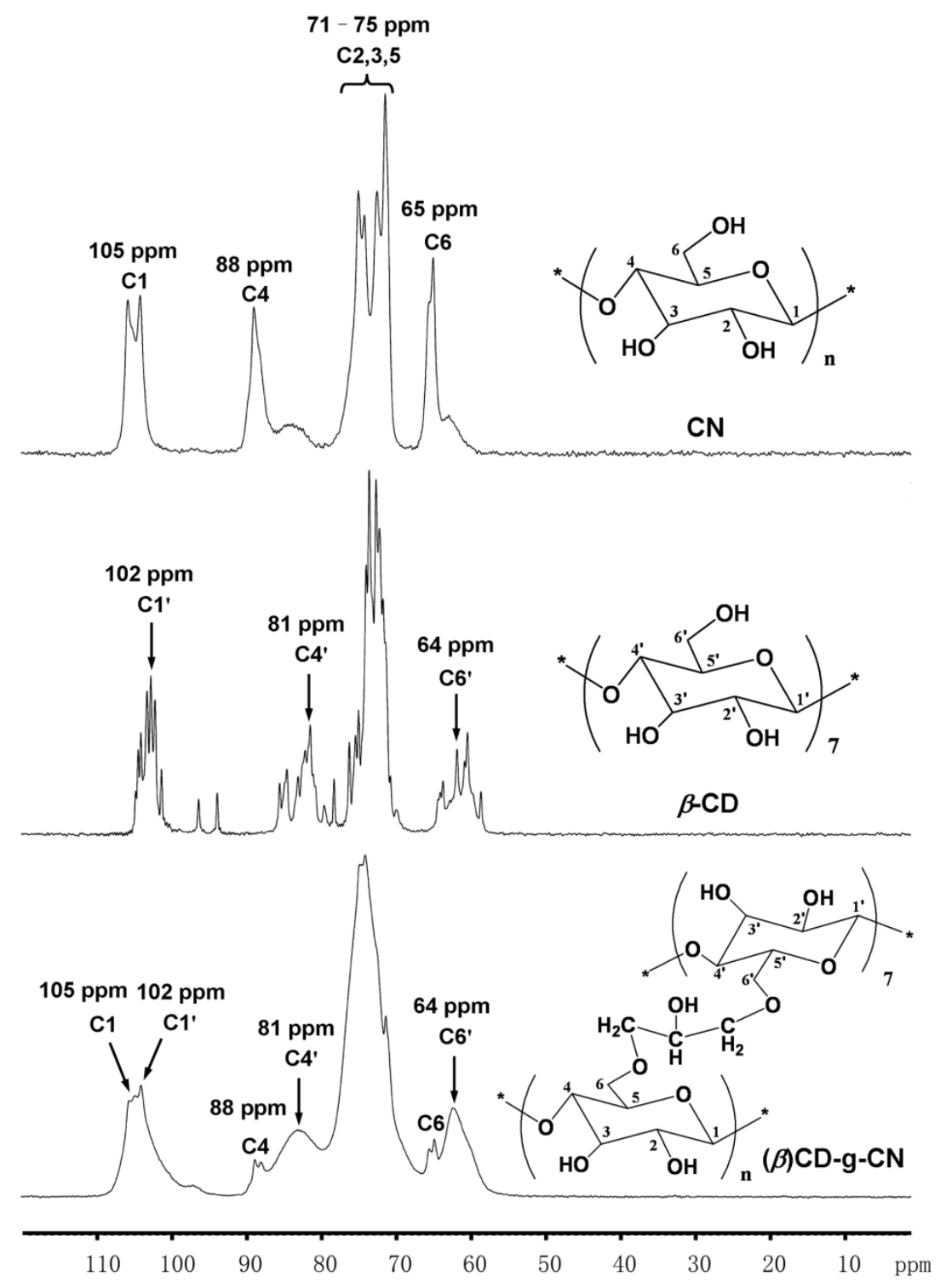

Figure 2. ${ }^{13} \mathrm{C}(\mathrm{CP} / \mathrm{MAS})$ solid-state $\mathrm{NMR}$ spectra of $\mathrm{CN}, \beta-\mathrm{CD}$ and $(\beta) \mathrm{CD}$-g-CN. 

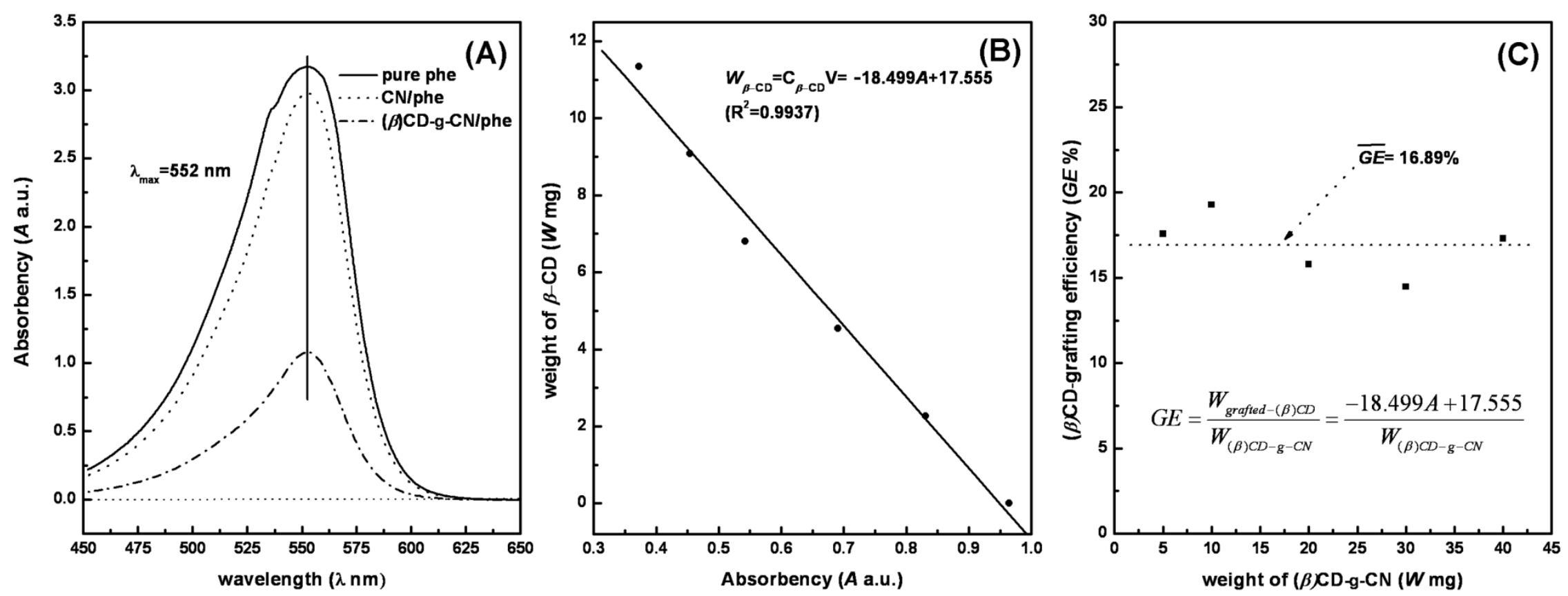

Figure 3. (A) UV absorption spectra for pure phenolphthalein solution (phe), phe solution treated with pristine $\mathrm{CN}(\mathrm{CN} / \mathrm{phe})$, and phe solution treated with $\beta$-CD grafted $\mathrm{CN}((\beta) \mathrm{CD}$-g-CN/phe); (B) standard curve and equation from $\beta$-CD content and phe absorbency; (C) $\beta$-CD grafting efficiency from $(\beta) \mathrm{CD}-\mathrm{g}-\mathrm{CN}$ samples with different quantities. 

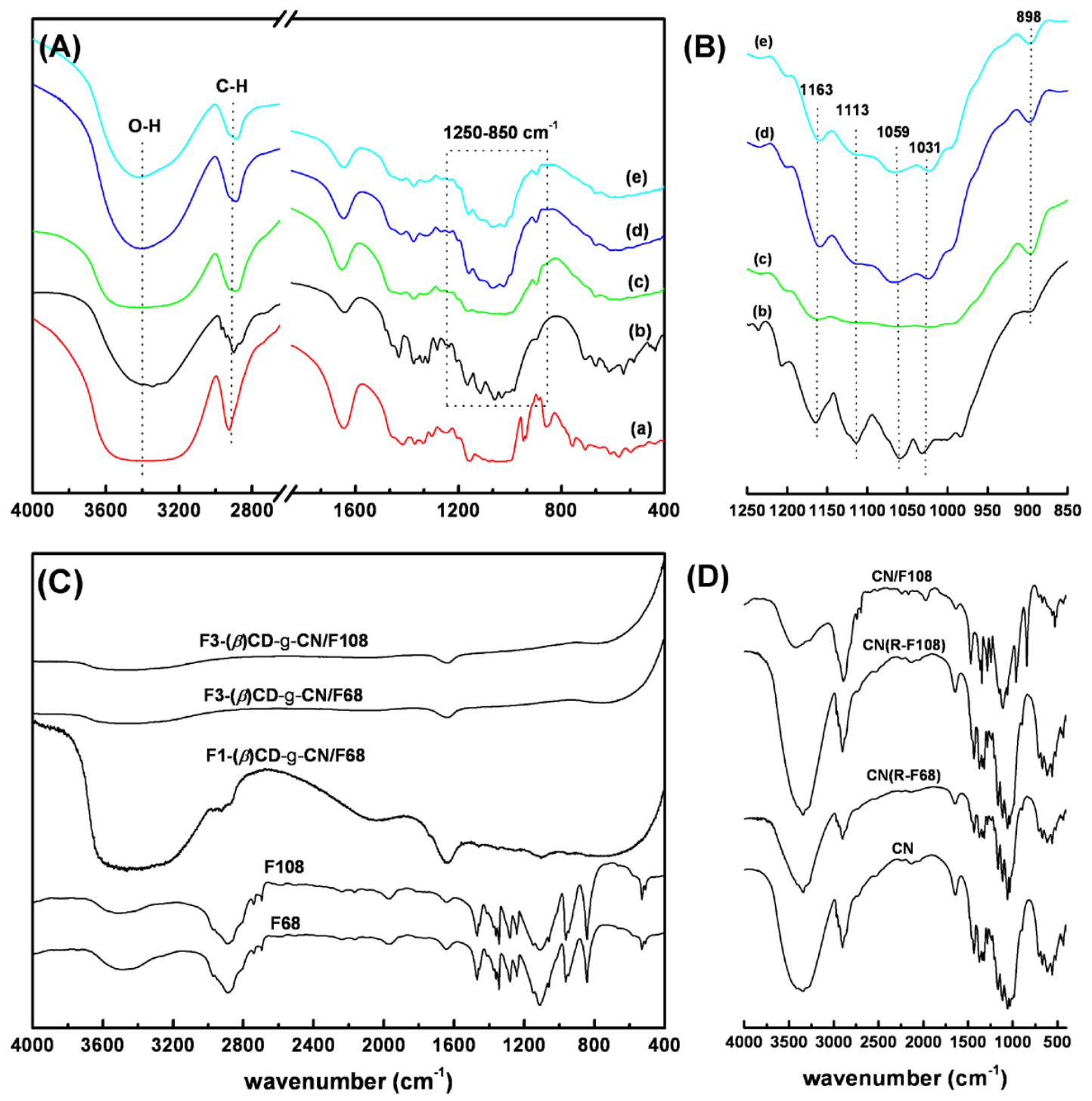

Figure 4. FTIR spectra for (A and B) cellulose nanocrystals before and after chemical modifications: (a) $\beta$-CD (b) $\mathrm{CN}$ (c) $(\beta) \mathrm{CD}$-g-CN (d) $(\beta) \mathrm{CD}-\mathrm{g}-\mathrm{CN} / \mathrm{F} 68$ (e) $(\beta) \mathrm{CD}$-g$\mathrm{CN} / \mathrm{F} 108$; (C) pure Pluronic polymers and supernatants from the preparation of $(\beta) \mathrm{CD}-\mathrm{g}-\mathrm{CN} /$ Pluronic complexes with the treatment of successive solubilizationcentrifugation (F1 and F3 represent the supernatant after the treatment for one and three times); (D) comparisons between pristine $\mathrm{CN}, \mathrm{CN} / \mathrm{F} 108$ with physically adsorbed Pluronic F108, and CN(R-Pluronic) from the purification of CN/Pluronic with the removal of adsorbed Pluronic using successive solubilization-centrifugation method. 

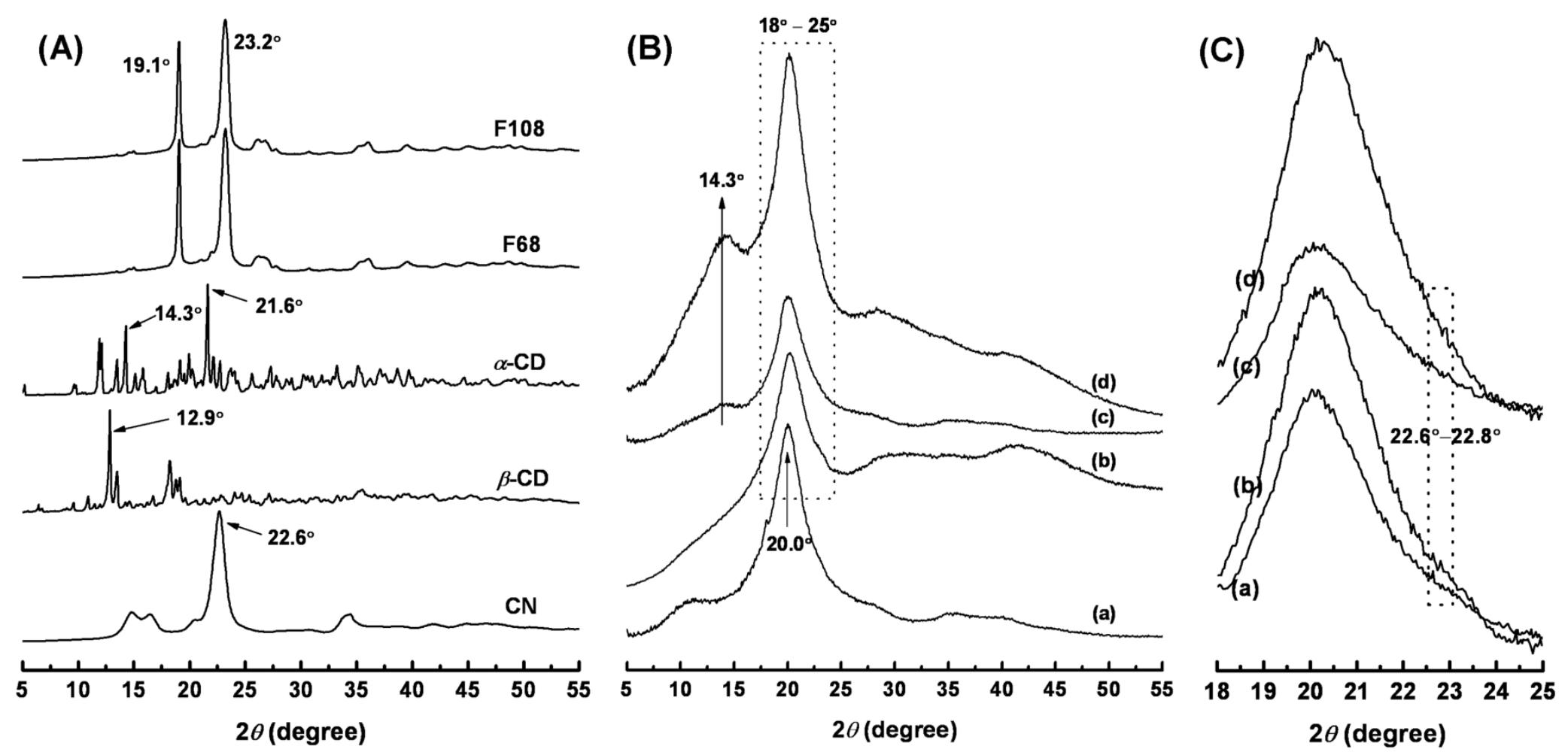

Figure 5. X-ray diffraction patterns of (A) original materials: $\mathrm{CN}, \beta-\mathrm{CD}, \alpha-\mathrm{CD}$, Pluronic F68 and F108; (B and C) inclusive complexes of (a) $(\beta)$ CD-g-CN/F68, (b) ( $\beta)$ CD-g-CN/F108, (c) $(\beta)$ CD-g-CN/F68- $\alpha(C D),(d)(\beta) C D-g-C N / F 108-\alpha(C D)$. 


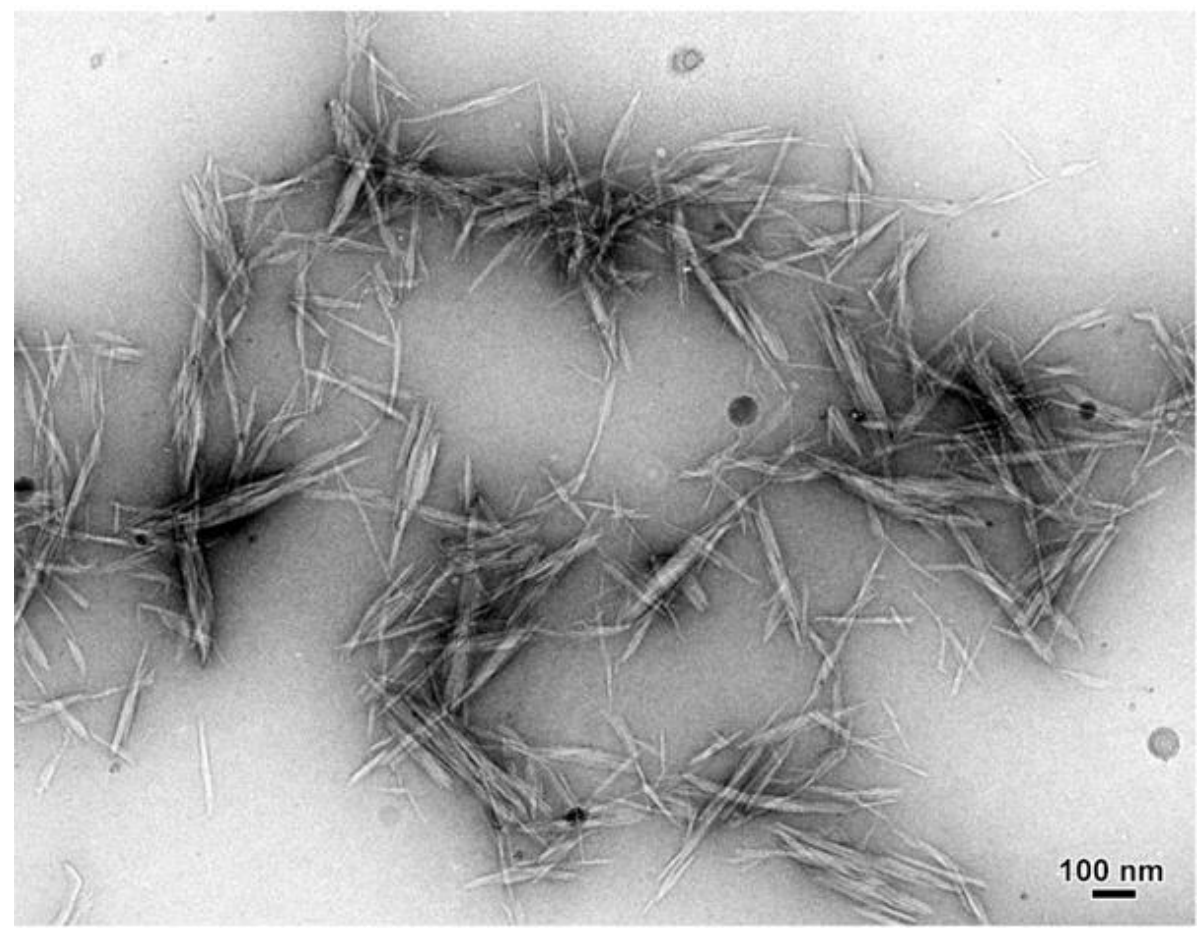

Figure 6. TEM micrographs of cellulose nanocrystals. 

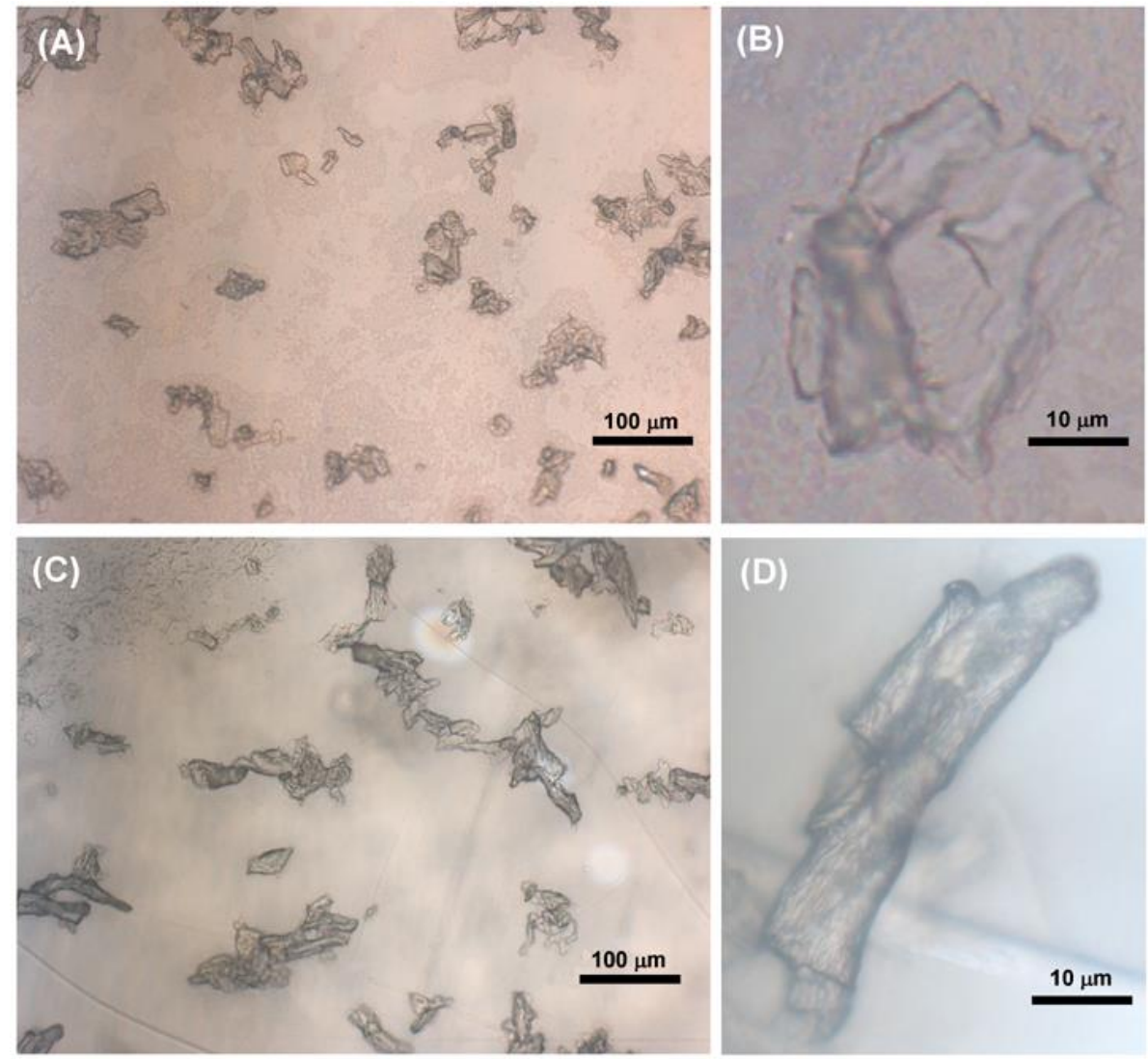

Figure 7. Optical microscopy images of in situ supramolecular hydrogels of (A and B) $\mathrm{CN}-\mathrm{CD} / \mathrm{F} 68-2,(\mathrm{C}$ and D) $\mathrm{CN}-\mathrm{CD} / \mathrm{F} 108-2$. 

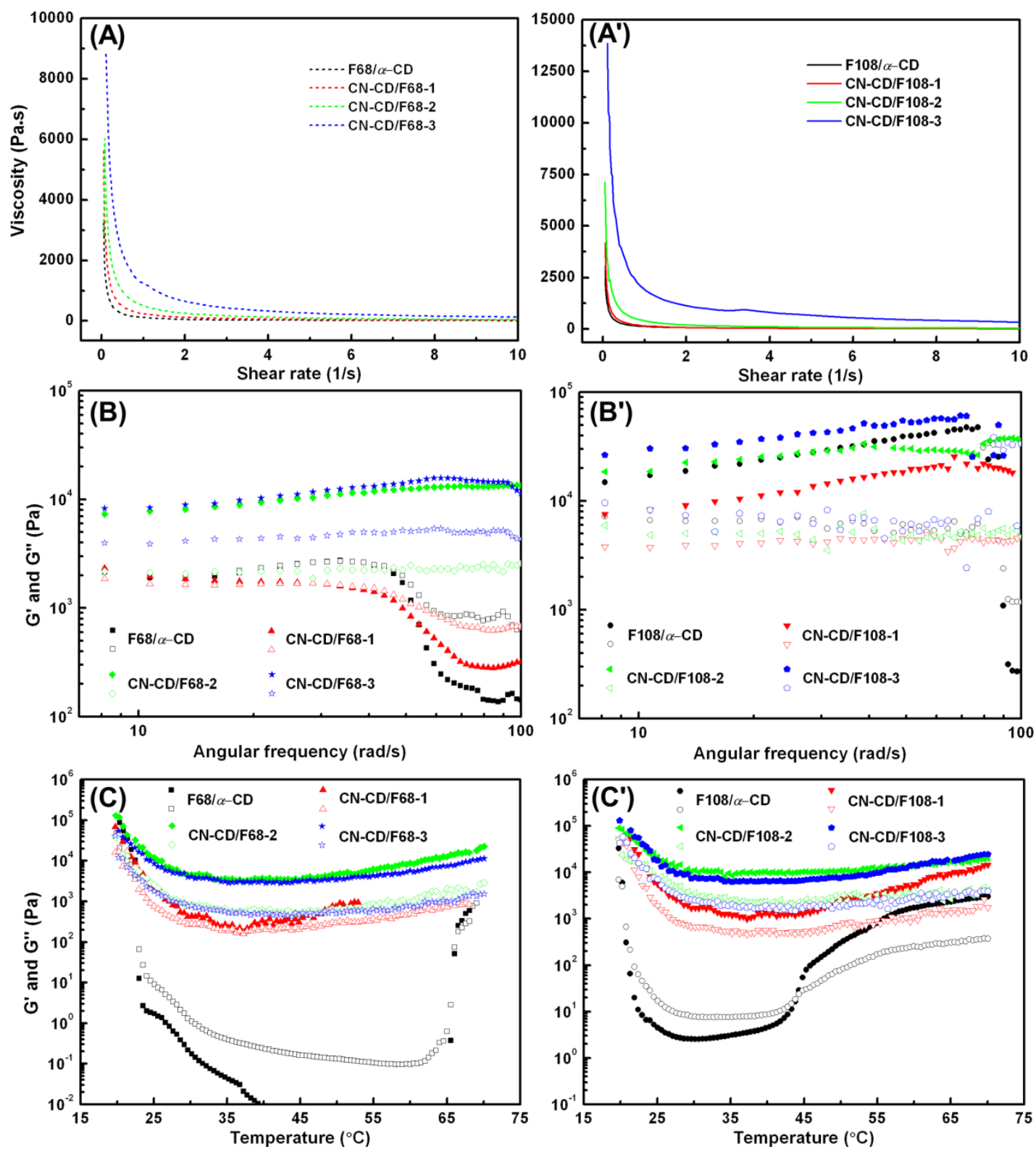

Figure 8. Rheological behavior of hydrogels: (A and $\left.A^{\prime}\right)$ viscosity vs. shear rate; (B and $\left.B^{\prime}\right)$ storage modulus ( $G^{\prime}$, filled symbols) and loss modulus ( $G^{\prime \prime}$, open symbols) vs. angular frequency; (C and $C^{\prime}$ ) $G^{\prime}$ (filled symbols) and $G^{\prime \prime}$ (open symbols) vs. temperature at a fixed frequency of $20 \mathrm{rad} / \mathrm{s}$ and $50 \mathrm{~Pa}$ shear stress in the range of 20 $70{ }^{\circ} \mathrm{C}$. 

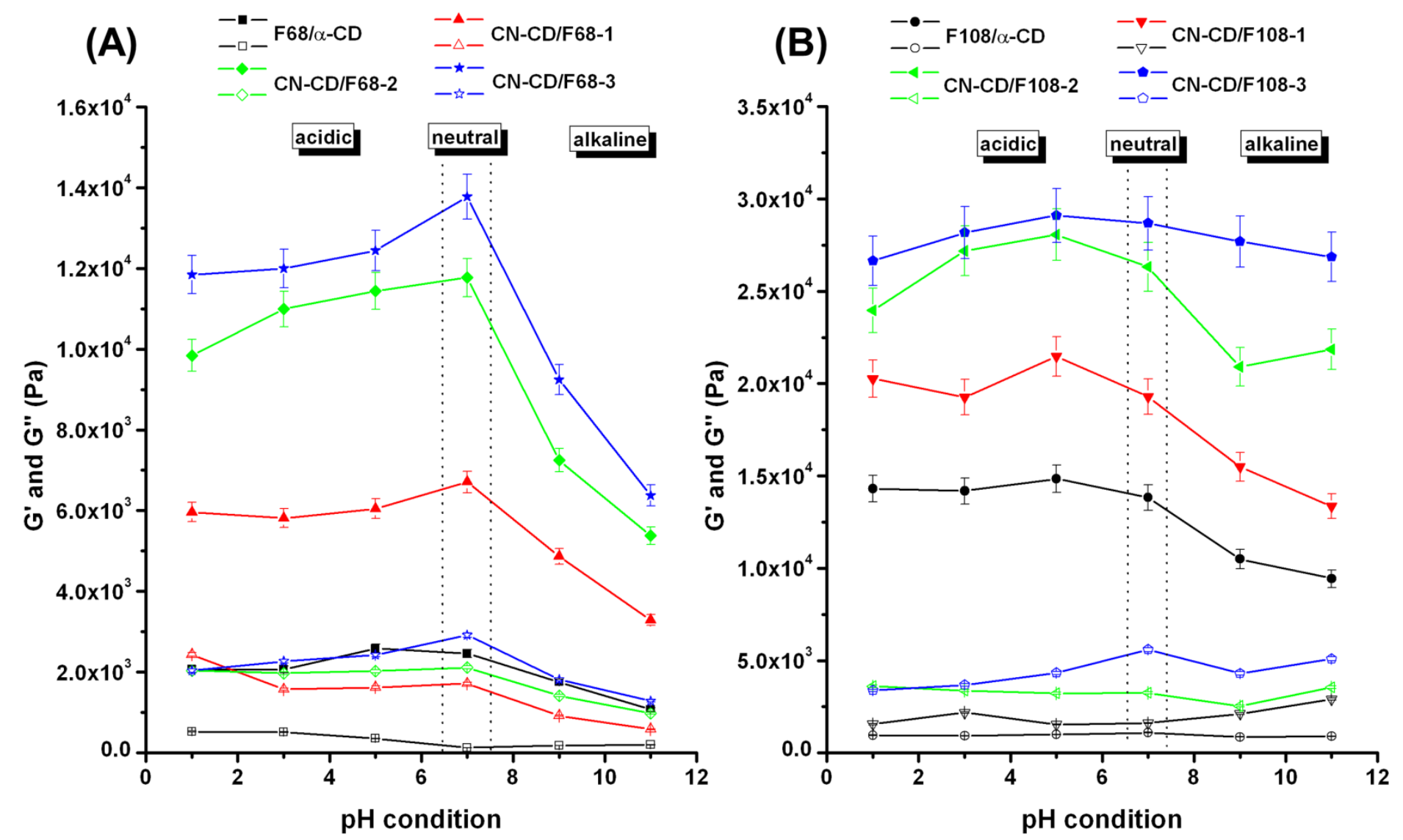

Figure 9. Evolution of $\mathrm{G}^{\prime}$ (filled symbols) and $\mathrm{G}^{\prime \prime}$ (open symbols) for various hydrogels under different $\mathrm{pH}$ conditions at a fixed frequency of 1 $\mathrm{Hz}$ with $50 \mathrm{~Pa}$ shear stress at $20^{\circ} \mathrm{C}$. 

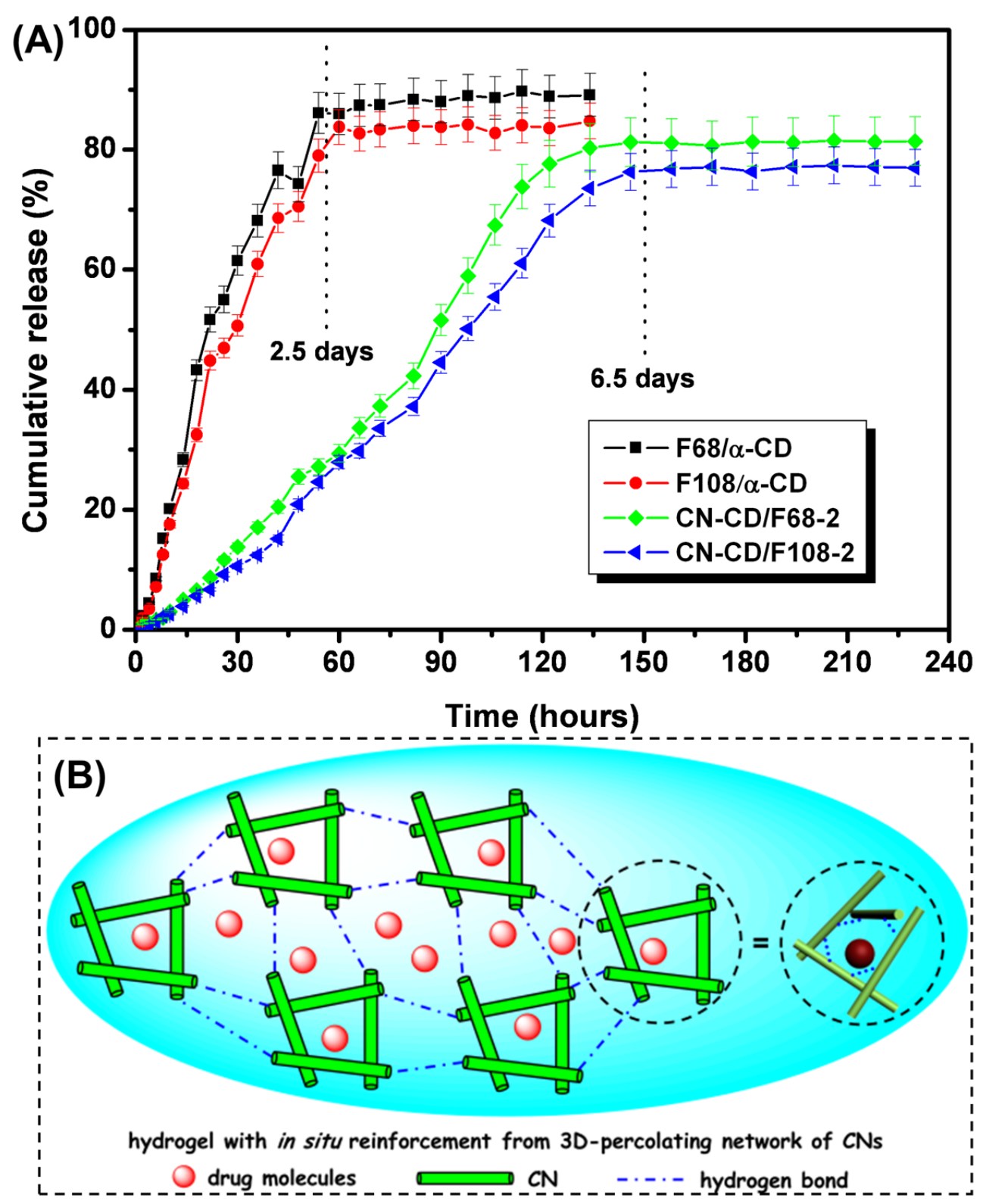

Figure 10. (A) In vitro release profiles of doxorubicin $\cdot \mathrm{HCl}$ for hydrogels with different compositions; (B) possible "locking effect" from the linkage between nanoparticles. 
Table of Contents Graphic

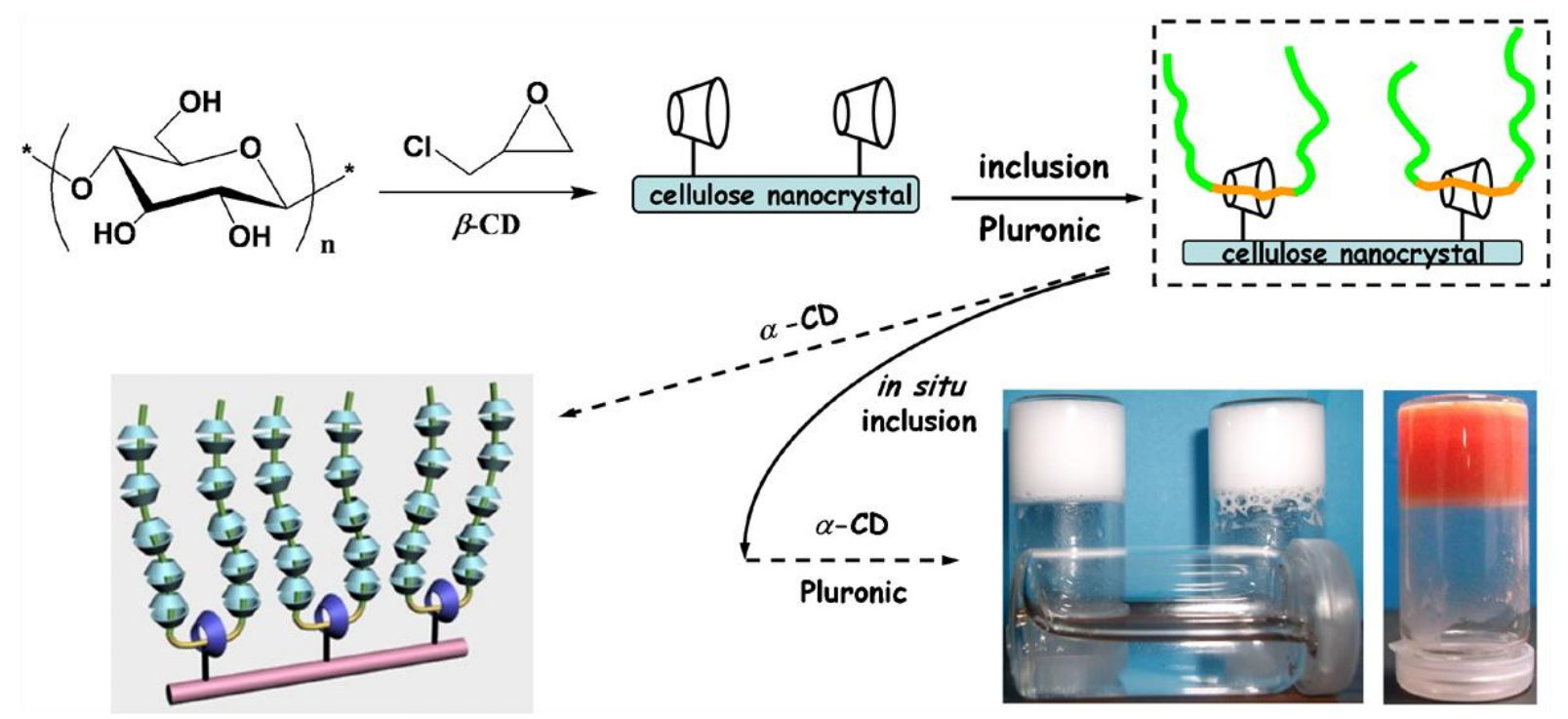

